Agnes N. Tirona-Remulla, MD Department of Otorhinolaryngology College of Medicine - Philippine General Hospital University of the Philippines Manila
Correspondence: Agnes N. Tirona-Remulla, MD

Department of Otorhinolaryngology

Ward 10, Philippine General Hospital

Taft Ave., Ermita, Manila 1000

Phone: (632) 5264360

Fax: (632) 5255444

Email: atremulla95@yahoo.com.ph

Reprints will not be available from the author.

No funding support was received for this study. The author signed a disclosure that she has no proprietary or financial interest with any organization that may have a direct interest in the subject matter of this manuscript, or in any product used or cited in this article.

\section{Pediatric Obstructive Sleep Apnea and Adenotonsillectomy}

Obstructive sleep apnea (OSA) in children is one of the most common problems encountered by the otolaryngologist. It was described frequently in adults but was not clearly defined as of true medical significance in children until 1976. Since then, rapid advances in technology and increasing recognition have propelled pediatric sleep apnea into both fame and notoriety.

Snoring is the hallmark of sleep disordered breathing. It occurs in up to $27 \%$ of schoolaged children ${ }^{2-10}$ and peaks at 2-8 years. This is coincident with the peak in size and degree of immunologic activity of the tonsils ${ }^{11}$. The reported prevalence of sleep apnea in this age group is $2-3 \%{ }^{10,12}$. Snoring again increases in children 15 years and above with nearly half the males and a third of the females snoring habitually ${ }^{13}$. Characteristics of pubertal children with OSA closely mimic adult patterns and are usually addressed as such.

Airway collapse in OSA is dictated by many factors. Anatomic obstruction caused by adenotonsillar hypertrophy is the most readily recognizable etiology. Certain craniofacial characteristics also result in a smaller airway. Moreover, functional pharyngeal muscle tone varies in response to sleep state, pressure-flow airway mechanics and respiratory drive to determine the cross sectional area of the upper airway ${ }^{14}$. In children with primary snoring, narrowing occurs at the level of the soft palate. In those with OSA, collapse is at the level of the tonsils and adenoids ${ }^{12}$. Interestingly several researches have failed to demonstrate significant correlation between adenotonsillar size and OSA ${ }^{14-18}$. This discrepancy is now being attributed primarily but not solely to the increased incidence of childhood obesity. Upper airway, neck, chest and abdominal fat deposition give rise to upper airway narrowing, increased mass loading, decreased chest and diaphragmatic excursions ${ }^{14}$. These result in an obstructive as well as restrictive pattern of respiratory compromise. Although obese children may have concomitant adenotonsillar hypertrophy, addressing this exclusively rarely leads to resolution of OSA.

The consequences of untreated childhood OSA encompass a broad range of morbidities including behavioral disturbances and learning deficits, cardiovascular disease, metabolic disturbances, somatic growth compromise, decreased quality of life and psychiatric illness ${ }^{14}$. Mouth breathing is a clinical presentation worthy of special mention. It has been known that adenoid hypertrophy resulting in chronic mouth breathing leads to "adenoid facies." This is characterized by an incompetent lip seal, narrow upper dental arch, increased anterior face height, steep mandibular plane angle, and a retrognathic mandible ${ }^{19-20}$. Craniofacial development progresses rapidly and retains its plasticity until early puberty (12 or 13 years). Thereafter, growth slows down as the adult face begins to set ${ }^{21}$. If mouth breathing is left 
untreated by this age the probability that the child will eventually develop adult-pattern OSA is greater. Fortunately, not all children develop these complications. Environmental exposure and genetic susceptibility certainly play a role in making a child more vulnerable to the effects of OSA. On the other hand, some of these morbidities may not be completely reversible despite treatment ${ }^{14,22}$. Therefore, timely and appropriate management of OSA is crucial in ensuring conditions for optimal development.

Tonsillectomy and adenoidectomy remain the primary mode of treatment for childhood OSA. Fear of rheumatic fever and its complications traditionally prompted immediate removal of the tonsils and adenoids. In 1978, OSA was not documented as an indication for tonsillectomy. An increasing trend was demonstrated such that in 1986 $19 \%$ of cases were due to OSA ${ }^{22}$. By 2003 , upper airway obstruction was the reason for surgery in $96 \%$ of tonsillectomies performed in children less than 36 months over a period of 2 years in a tertiary center ${ }^{23}$.

A meta-analysis of 14 studies reporting polysomnographic outcomes of tonsillectomy and adenoidectomy showed a summary success rate of $82.9 \%{ }^{24}$. Significant improvement in quality of life based on validated questionnaires measuring sleep disturbance, physical symptoms, emotional symptoms, hyperactivity and daytime functioning without supporting polysomnographic results have also been reported ${ }^{25-30}$. However, this still leaves a number of children with residual disease. Readily identifiable risk factors for surgical failure are untreated nasal obstruction, maxillomandibular deficiency, obesity and a high respiratory index ${ }^{14,31,32}$. Further treatment using medications, additional surgery or positive airway pressure therapy is usually necessary for this group of patients.

The first 24 hours after surgery is probably the most critical time for developing complications. Patients have deeper sleep due to chronic poor sleep quality and sedation or may be placed in supine position ${ }^{37}$. OSA as an operative diagnosis automatically increases the risk of the patient. Other factors are low weight, obesity especially those with associated co-morbidities (hypertension, asthma and type II diabetes), age less than 3 years and those with severe pulmonary hypertension ${ }^{33-37}$. Identified problems are supraglottic obstruction, breath holding, desaturation on induction and emergence ${ }^{37}$. In children less than 6 years $6.4 \%$ experienced morbidities which were primarily respiratory. More than half of these children $(57.7 \%)$ had desaturations necessitating use of an artificial airway via nasopharyngeal airway or endotracheal intubation and $18 \%$ had significant chest findings on radiograph particularly atelectasis, infiltrates and pulmonary edema ${ }^{36}$. Children less than 3 years old have nearly a 2-fold increased risk for respiratory complications ${ }^{36}$.

Risk-assessment prior to surgery is essential in achieving a safe perioperative outcome. Close coordination with other concerned physicians particularly pediatric subspecialists and anesthesiologists is fundamental. The hospital wherein the procedure will be conducted should have provisions for thorough intra- and post-operative monitoring. The decision to admit to the ICU after surgery is dictated by severity of illness, the presence of co-morbidities and young age.

Pediatric obstructive sleep apnea is an entity in evolution. Heterogenous patient profiles especially in the face of rising obesity, changing syndrome definitions and polysomnographic parameters, innovations in treatment and even legal issues will continue to challenge every otolaryngologist. Notwithstanding, otolaryngology should remain in the foreground in treating pediatric OSA. Despite attendant risks and limitations, pediatric sleep surgery in the hands of the informed otolaryngologist is still the most useful tool in helping children recover from sleep disordered breathing. 


\section{REFERENCES}

1. Guilleminault C, Eldridge FL, Simmons FB, Dement WC. Sleep apnea in eight children. Pediatrics 1976;58:23-30.

2. O'Brien $\mathrm{LM}$, Holbrook CR, Mervis CB, et al.Sleep and neurobehavioral characteristics in 5-7-yearold hyperactive children. Pediatrics 2003;111:554-63.

3. Urschitz MS, Guenther A, Eitner $\mathrm{S}$, et al. Risk factors and natural history of habitual snoring Chest 2004;126:790-800.

4. Ersu R, Arman AR, Save D, et al. Prevalence of snoring and symptoms of sleep-disordered breathing in primary school children in Istanbul. Chest 2004;126:19-24.

5. Kaditis AG, Finder J, Alexopoulos El, et al.Sleep-disordered breathing in 3,680 Greek children Pediatr Pulmonol 2004;37:499-509.

6. Rosen CL, Larkin EK, Kirchner HL, et al. Prevalence and risk factors for sleep-disordered breathing in 8- to 11-year-old children: association with race and prematurity. J Pediatr 2003;142:383-9.

7. Montgomery-Downs $\mathrm{HE}, \mathrm{O}^{\prime} B$ rien $\mathrm{LM}, \mathrm{Holbrook} C \mathrm{R}$, et al. Snoring and sleep-disordered breathing in young children: subjective and objective correlates. Sleep 2004;27:87-94.

8. Montgomery-Downs HE, Gozal D. Sleep habits and risk factors for sleep-disordered breathing in infants and young toddlers in Louisville, Kentucky. Sleep Med 2006;7(3):211-9.

9. Schechter MS. Section on pediatric pulmonology,subcommittee on obstructive sleep apnea syndrome. Technical report: diagnosis and management of childhood obstructive sleep apnea syndrome. Pediatrics 2002;109:e69.

10. Ali NJ, Pitson DJ, Stradling JR. Snoring, sleep disturbance, and behaviour in 4-5 year olds. Arch Dis Child. 1993;68:360-366.

11. Marcus CL. Sleep-disordered breathing in children. Am J Respir Crit Care Med 2001;164(1):1630.

12. Isono S, Shimada A, Utsugi M, et al. Comparison of static mechanical properties of the passive pharynx between normal children and children with sleep-disordered breathing. Am J Respir Crit Care Med 1998;157:1204-12.

13. Ohayon, $M$ at al. Snoring and breathing pauses during sleep: telephone interview survey of a United Kingdom population sample. BMJ 1997;314:860.

14. Dayyat E, Kheirandish-Gozal L, Gozal D. Childhood obstructive sleep apnea:one or two distinct disease entities? Sleep Med Clin 2. 2007; 433-444.

15. Lam YY, Chan EY, Ng DK, et al. The correlation among obesity, apnea-hypopnea index, and tonsil size in children. Chest 2006;130(6):1751-6.

16. Fregosi RF, Quan SF, Kaemingk KL, et al. Sleep disordered breathing, pharyngeal size and soft tissue anatomy in children. J Appl Physiol. 2003;95(5):2030-8.

17. Li AM, Wong E, Kew J, et al. Use of tonsil size in the evaluation of obstructive sleep apnoea. Arch Dis Child 2002;87(2):156-9.

18. Erdamar B, Suoglu Y, Cuhadaroglu C, et al. Evaluation of clinical parameters in patients with obstructive sleep apnea and possible correlation with the severity of the disease. Eur Arch Otorhinolaryngol 2001;258(9):492-5.

19. Peltomäki T. The effect of mode of breathing on craniofacial growth--revisited. Eur J Orthod. 2007 Oct;29(5):426-9. Epub 2007 Sep 4.

20. Lessa FC, Enoki C, Feres MF, Valera FC, Lima WT, Matsumoto MA. Breathing mode influence in craniofacial development. Rev Bras Otorrinolaringol (Engl Ed). 2005 Mar-Apr;71(2):156-60. Epub 2005 Aug 2.

21. Enlow DH, Hans MG. Essentials of Facial Growth. New York: W..B.Saunders Co.1996.

22. Rosenfeld RM. Green RP. Tonsillectomy and adenoidectomy: changing trends. Ann Otol Rhinol Laryngol 1990;99:187-91.

23. Ross, AT, Kazahaya, K, Tom, LWC. Revisiting outpatient tonsillectomy in young children. Otolaryngol Head Neck Surg. 2003;128(3):326-331.

24. Brietzke SE. The effectiveness of tonsillectomy and adenoidectomy in the treatment of pediatric obstructive sleep apnea/hypopnea syndrome: a meta-analysis. Otolaryngol Head Neck Surg. 2006; 134(6): 979-84.

25. Constantin E, KermackA, Nixon GM,Tidmarsh L, DucharmeFM, Bouillette RT. Adenotonsillectomy improves sleep, breathing, and quality of life but not behavior. J Pediatr. 2007;150:540-6.

26. Montiel A, de Diego J, Prim MP, Martinez MA, Perez, Fernandez E, Rabanal I. Quality of life after surgical treatment of children with obstructive sleep apnea: long term results. Int J Pediatr Otorhinolaryngol. Sep 2006;70(9):1575-9.

27. Flanary VA. Long-term effect of adenotonsillectomy on quality of life in pediatric patients. Laryngoscope 2003;113:1639-1644.

28. Stewart MG, Glaze DG, Friedman EM, Smith EO, Bautista M. Quality of life and sleep study findings after adenotonsillectomy in children with obstructive sleep apnea. Arch Otolaryngol Head Neck Surg 2005;131:308-314.

29. Mitchell RB, Kelly J, Call E, Yao N. Quality of life after adenotonsillectomy for obstructive sleep apnea in children. Arch Otolaryngol Head Neck Surg. 2004;130:190-194.

30. Avior G, Fishman G, Leor A, Sivan Y, Kaysar N, Derowe A. The effect of tonsillectomy and adenoidectomy on inattention and impulsivity as measured by the test of variables of attention (TOVA) in children with obstructive sleep apnea syndrome. Otolaryngol Head Neck Surg 2004;131:367-371.

31. Shine NP. Adenotonsillectomy for obstructive sleep apnea in obese children: effects on respiratory parameters and clinical outcome. Arch Otolaryngol Head Neck Surg 01 OCT 2006; 132(10): $1123-7$

32. Guilleminault C, Huang YS, Glamann C, Li K, Chan A Adenotonsillectomy and obstructive sleep apnea in children: a prospective survey. Otolaryngol Head Neck Surg Feb 2007; 136(2): 169-75. 3. Sanders JC, King MA, Mitchell RB, Kelly JP. Perioperative complications of adenotonsillectomy in children with obstructive sleep apnea syndrome. Anesth Analg. 2006; 103(5): 1115-21.

34. Carmosino MJ, Friesen RH, Doran A, Ivy DD. Perioperative complications in children with pulmonary hypertension undergoing noncardiac surgery or cardiac catheterization. Anesth Analg. 2007; 104(3): 521-7.

35. Tait AR, Voepel-Lewis T, Burke C, Kostrzewa A, Lewis I. Incidence and risk factors for perioperative adverse respiratory events in children who are obese. Anesthesiology. 2008;108:375-80.

36. Statham MM, Elluru, RG, Buncher R, Kalra M. Adenotonsillectomy for obstructive sleep apnea syndrome in young children. Arch Otolaryngol Head Neck Surg 2006;132:476-480.

37. Rosenberg J, Rasmussen GI, Wojdemann KR, et al. Ventilatory pattern and associated episodic hypoxaemia in the late postoperative period in the general surgical ward. Anaesthesia 1999;54:323-8. 